\title{
Postharvest Incidence of Stem End Rot in 'Hayward' Kiwifruit Is Related to Preharvest Botrytis cinerea Colonization of Floral Parts and Latent Infection
}

\author{
Danae Riquelme-Toledo, ${ }^{1}$ Héctor Valdés-Gómez, ${ }^{1}$ Marc Fermaud, ${ }^{2}$ and Juan Pablo Zoffoli ${ }^{1, \dagger}$ \\ ${ }^{1}$ Pontificia Universidad Católica de Chile. Facultad de Agronomía e Ingeniería Forestal. Departamento de Fruticultura y \\ Enología. Vicuña Mackenna 4860, P.O. Box 7820436, Santiago, Chile \\ 2 INRA, UMR 1065 "Santé et Agroécologie du Vignoble”, SAVE, Bordeaux Science Agro, ISVV, Centre INRA de Bordeaux, \\ France
}

\begin{abstract}
Stem end rot (SER) caused by Botrytis cinerea is the primary postharvest disease in the Chilean kiwifruit industry. Relationships between the postharvest occurrence of SER in 'Hayward' kiwifruit and the temporal dynamics of earlier B. cinerea colonization of the floral parts (petals, sepals, receptacles, styles) was studied in five orchards over two consecutive seasons in Chile. Weather conditions in the first season favored B. cinerea infection with roughly constant colonization of floral parts up to about 120 days after full bloom, but colonization then increased up until

infections at harvest were the best predictors $(\mathrm{r}>0.8)$ of postharvest SER. The number of preharvest infection periods calculated using temperature, leaf wetness, and relative humidity satisfactorily predicted SER incidence by an exponential model, $\mathrm{R}^{2}=0.90, P<0.001$. Results indicated environmental variables play key roles in the temporal dynamics of B. cinerea colonization. Quantification of latent $B$. cinerea infections in asymptomatic fruit close to harvest, is a practicable way to predict later incidence of SER during storage.
\end{abstract} harvest. In the second season, colonization was roughly constant throughout. Latent infections of the fruit occurred in both seasons but were high in the first season and low in the second. Incidence of latent
Keywords: epidemiology, climate/weather effects, disease development and spread, fungi, abiotic, pathogen survival
Chile is one of the world's largest producers of 'Hayward' kiwifruit (Actinidia deliciosa (A. Chev.) C.F. Liang et A.R. Ferguson) and the second largest exporter of kiwifruit in the Southern Hemisphere, with a production area of more than 8,700 ha (https://www. odepa.gob.cl/panorama_2019/86/,2019). The Chilean kiwifruit is produced primarily for export by ship to distant markets in Europe and Asia (https://www.prochile.gob.cl/landing/sectores-productivos/, 2019). Hence, it is crucial the storage life of the fruit is as long as possible. Postharvest technologies to complement cold storage, such as curing (holding fruit at ambient temperatures prior to cold storage to promote wound healing), controlled atmosphere storage, modified atmosphere packaging (MAP), and 1-methylcyclopropene (1-MCP) application, are widely used to reduce kiwifruit softening and extend storage life (Lallu and Burdon 2007; Park et al. 2015; Pennycook and Manning 1992; Poole and McLeod 1994). Despite these efforts to maximize fruit quality to market, postharvest decay remains the primary risk factor affecting Chile's kiwifruit trade.

Stem end rot (SER) is caused by Botrytis cinerea Pers.:Fr. and Botrytis prunorum E.E. Ferrada \& Latorre (Elfar et al. 2017). Stem end rot is the postharvest disease of greatest importance to the kiwifruit industry, and particularly for 'Hayward' (Manning et al. 2010; Park et al. 2015). Losses due to SER are highly variable among seasons and among orchards, indicating both weather effects and also microclimate/management effects (Michailides and Morgan 1996; Pennycook 1985). Incidence of SER is around 2 to $3 \%$ in New Zealand (Beever et al. 1984; Michailides and Morgan 1996), up to 15\% in Chile (Farías 2009), and up to $20 \%$ in Italy (Bisiach et al. 1984).

${ }^{\dagger}$ Corresponding author: J. P. Zoffoli; zoffolij@uc.cl

Funding: Financial support was provided by a CONICYT doctorate scholarship, No. 21170522.

The author(s) declare no conflict of interest.

Accepted for publication 26 September 2019

C 2020 The American Phytopathological Society
B. cinerea is a polyphagous fungus that has the ability to colonize different tissues within a host (Giraud et al. 1999; Latorre et al. 2015; Martinez et al. 2005). In kiwifruit, B. cinerea can colonize flowers, leaves, and fruit tissues. These become potential inoculum sources for SER when environmental conditions are favorable and the fruit is susceptible (Elmer et al. 1997; Jarvis 1994). The symptoms of SER occur primarily in stored kiwifruit, while preharvest expression of the disease is uncommon (Pennycook 1985; Sharrock and Hallett 1992).

Similar to other postharvest diseases (Fourie et al. 2002; Mari et al. 2003; Rivera et al. 2013), B. cinerea infection in kiwifruit occurs in the field, through the colonization of sepals and receptacles relatively early in fruit development, and well before harvest (Michailides and Elmer 2000; Michailides and Morgan 1996). It can also occur in the small wound in the stem end caused by picking (Elmer and Michailides 2007; Sharrock and Hallett 1992).

Thus, $B$. cinerea produces latent infections that are later activated when the physiological and biochemical conditions of the host and the environmental conditions are optimal for development of the disease (Michailides et al. 2010; Prusky et al. 2013). Paraquat and/or freezing temperature treatments have been used to demonstrate the presence of nonvisible pathogens in apple (Biggs 1995), grape (Holz et al. 2003; Sanzani et al. 2012), peach (Emery et al. 2000), sweet cherry (Adaskaveg et al. 2000), prune (Luo and Michailides 2001; Luo et al. 2001), and other fruit hosts (Fourie et al. 2002; Northover and Cerauskas 1994; Prusky et al. 1981). However, few studies have described latent infections in immature kiwifruit during fruit development or their potential value as predictors of postharvest SER.

Airborne conidial concentrations (ACC) and environmental conditions are two key factors that influence the success of the establishment of a latent infection (Elad and Evensen 1995; Prusky et al. 2013; Verhoeff 1974). Temperature, relative humidity, and wetness duration have been described as the main environmental factors that affect the infection and dispersion of B. cinerea in table grapes (Broome et al. 1995; English et al. 1989), blueberry (Rivera et al. 2013), and strawberry (Bulger et al. 1987; Xu et al. 2000). However, the effects of such factors on SER in kiwifruit have not yet been identified.

In Chile, the major strategies to control SER during cold storage involve applications of chemical products at flowering and/or at harvest (Latorre and Pak 2003). In addition, postharvest 'curing' is used to induce defense mechanisms within the fruit (Pennycook and 
Manning 1992; Poole and McLeod 1994; Wurms et al. 1997). However, these control strategies were developed based on epidemiological work carried out on B. cinerea under field conditions in New Zealand and the United States (California). The climatic conditions in Chile are distinct, so the conclusions from these studies may not apply directly here. Thus, knowledge is needed of the temporal dynamics of $B$. cinerea colonization and infection during fruit development in Chile. This new information should permit more appropriate recommendations for SER control and more accurate risk assessments to be made under Chilean growing conditions. Therefore, the objectives of this study were to determine the temporal dynamics of $B$. cinerea colonization in the floral parts and in fruit of 'Hayward' kiwifruit during development and their relationships with SER occurrence during the fruit's subsequent period of cold storage. This study included the somewhat contrasting weather conditions of two sequential growing seasons.

\section{Materials and Methods}

Experimental site characteristics. The study was conducted during the 2016 (S1) and 2017 (S2) growing seasons, in Cachapoal Valley (CV) and South of the Maule Valley (SMV). Both are major production areas for 'Hayward' kiwifruit in the Central Valley in Chile. These areas have a Mediterranean climate (Csb1) according to the Köpper climate classification (Sarricolea et al. 2017). The historical mean annual temperature range is $14-16^{\circ} \mathrm{C}$; the coldest month is July (midwinter) $8-9^{\circ} \mathrm{C}$; and the hottest month is January (midsummer) $20-22^{\circ} \mathrm{C}$. The main rainfall period is concentrated between May and August, with the mean annual rainfalls varying between $446 \mathrm{~mm}$ in CV and $773 \mathrm{~mm}$ in SMV (www.ine.cl).

Five commercial 'Hayward' kiwifruit orchards were selected: three (O1, O2, and O3) in CV and two (O4 and O5) in SMV (Table 1). The vines in all orchards were trained to a pergola system and irrigated and fertilized following the usual agronomic practices for commercial kiwifruit production in Chile (www.comitedelkiwi.cl).

Sampling. Fruit (or flower) sampling and capture of airborne conidia was done every 20 days. In S1, sampling started 60 days after full bloom (DAFB), when fruit diameter was $50 \mathrm{~mm}$ and the soluble solid content (SSC) was $4.3 \%$ and continued until harvest. In S2, sampling was from full bloom, and by 20 DAFB fruits were $20 \mathrm{~mm}$ in diameter and SSC was $4.0 \%$ and continued through to harvest when the SSC was 5.5-6.2\%. At full bloom, a total of 12 flowers per replicate were collected randomly. Later, fruit sampling used 27 fruit per replicate. Flower and fruit samples were transported to the laboratory in an ice chest and were stored at $10^{\circ} \mathrm{C}$ (flowers) or $0^{\circ} \mathrm{C}$ (fruit) until assessment. At harvest, 80 additional fruits per replicate were collected and stored at $0{ }^{\circ} \mathrm{C}$. Four replicates were used per sampling day. Sampling was carried out in four rows from 12 to 16 vines. To represent as much of the plot as possible, sampled vines-rows were spaced between 5 and $10 \mathrm{~m}$ apart. The same vine-rows were used to determine ACC. At full bloom, in S2, the sampling was carried out before a fungicide application. Due to technical problems, the $\mathrm{S} 1$ sampling was conducted from 60 DAFB instead of full bloom.

B. cinerea identification. $B$. cinerea and $B$. prunorum were identified from a total of 10 Botrytis colonies obtained from culture of sepals, receptacles, styles, fruit, and airborne conidial capture. Identification was based on the colonial characteristics, colony's conidial production, and the morphology of the conidia and conidiophores (Ferrada et al. 2016; Mirzaei et al. 2008; Pei et al. 2019). The culture medium was potato dextrose agar acidified with $0.5 \mathrm{ml}$ liter $^{-1}$ of $92 \% \mathrm{vol} / \mathrm{vol}$ lactic acid (APDA) with incubation at $20^{\circ} \mathrm{C}$ under $12 \mathrm{~h}$ light/dark cycle for 10 days. In addition, the morphological identification was corroborated with a molecular study using BLASTn analysis of the HSP60 gene fragment sequences.

Because $B$. cinerea was predominantly isolated from ACC, floral part colonization, latent infection, and SER ( $>90 \%$ of the total of $B o-$ trytis isolates in average), the results obtained were grouped with $B$. prunorum and then expressed as B. cinerea frequency.

Airborne conidial concentration (ACC). To determine the ACC for $B$. cinerea, airborne conidia were captured using an Andersen volumetric spore sampler for agar plates (Burkard Manufacturing. Co. Ltd., Rickmansworth, Hertfordshire, UK). This used a 100-hole sieve plate and three agar petri dishes $(90 \mathrm{~mm}$ diameter $)$ per replicate. The spore sampler was operated once per plate for $30 \mathrm{~s}$ (20 liter $\mathrm{min}^{-1}$ ) around midday and was located in two vine-row spaces, $1.8 \mathrm{~m}$ above the ground near the fruit and away from senescent leaves (Michailides and Elmer 2000; Mundy et al. 2012). The petri dishes contained APDA plus $0.1 \%$ vol/vol Igepal CO-630 (SigmaAldrich, Atlanta, GA) and were incubated for 7 to 10 days at $20-22^{\circ} \mathrm{C}$, with a $12 \mathrm{~h}$ day/night light cycle. Colony counts of $\mathrm{B}$. cinerea were expressed as colony forming units per cubic meter of air (CFU m ${ }^{-3}$ ) (Fernández Rodríguez et al. 2011).

$B$. cinerea colonization in floral parts and latent infection in fruit. Floral parts. To determine the presence of $B$. cinerea in floral parts of kiwifruit, petals $(n=72)$, sepals $(n=72)$, styles $(n=72)$, and receptacles $(n=12)$ were removed from 12 flowers or fruits per replicate and placed in labeled petri dishes containing APDA plus $0.1 \% \mathrm{vol} / \mathrm{vol}$ Igepal CO-630. Before plating, the various floral parts were surface-disinfected $(1 \% \mathrm{wt} / \mathrm{vol}$ sodium hypochlorite, plus $0.001 \% \mathrm{vol} / \mathrm{vol}$ Tween 80 for $2 \mathrm{~min}$ ), washed in sterile distilled water for $1 \mathrm{~min}$, and dried in a laminar flow hood. Plates were incubated for 10 days at $20-22^{\circ} \mathrm{C}$ under $12 \mathrm{~h}$ light. The results are reported as the percentages of floral parts colonized of the total number of samples.

Incidence of latent infections in fruit. Latent infections in fruit were determined using the overnight freezing incubation technique (ONFIT). Apparently healthy fruit ( $n=15$ per replicate) were randomly collected with peduncle attached on each sampling date and

Table 1. Characteristics of the 'Hayward' kiwifruit orchards used in the study

\begin{tabular}{|c|c|c|c|c|c|}
\hline \multirow[b]{2}{*}{ Characteristics } & \multicolumn{3}{|c|}{ Cachapoal Valley } & \multicolumn{2}{|c|}{ South of Maule Valley } \\
\hline & Orchard 1 & Orchard 2 & Orchard 3 & Orchard 4 & Orchard 5 \\
\hline Planting year & 1994 & 2006 & 2006 & 2004 & 2004 \\
\hline Location & $34^{\circ} 00^{\prime} \mathrm{S}, 70^{\circ} 42^{\prime} \mathrm{W}$ & $34^{\circ} 20^{\prime} \mathrm{S}, 70^{\circ} 42^{\prime} \mathrm{W}$ & $34^{\circ} 22^{\prime} \mathrm{S}, 70^{\circ} 54^{\prime} \mathrm{W}$ & $35^{\circ} 48^{\prime} \mathrm{S}, 71^{\circ} 48^{\prime} \mathrm{W}$ & $35^{\circ} 48^{\prime} \mathrm{S}, 71^{\circ} 49^{\prime} \mathrm{W}$ \\
\hline Plot (hectare) & 6.4 & 1.8 & 4.7 & 3.5 & 6.0 \\
\hline Row length $(\mathrm{m})^{\mathrm{a}}$ & $193.4(0.6)$ & $100(3.4)$ & $123.8(44.6)$ & $112.2(140.6)$ & 328.5 (11.6) \\
\hline Vine spacing $(\mathrm{m} \times \mathrm{m})$ & $5.0 \times 3.5$ & $3.5 \times 3.0$ & $4.7 \times 2.5$ & $3.5 \times 3.0$ & $3.5 \times 3.0$ \\
\hline Light interception $(\%)^{\mathrm{a}, \mathrm{b}}$ & $94.7(2.7)$ & $88.6(8.1)$ & $91.5(1.8)$ & $77.0(12.7)$ & $88.6(2.3)$ \\
\hline Irrigation system & Microsprinkler ${ }^{\mathrm{c}}$ & Drip irrigation & Drip irrigation & Microsprinkler $^{\mathrm{d}}$ & Microsprinkler $^{\mathrm{d}}$ \\
\hline Fungicide program ${ }^{\mathrm{e}}$ & Iprodione & Iprodione & Fenhexamid & Iprodione & Iprodione \\
\hline
\end{tabular}

a Values in parentheses corresponded to standard deviation.

b Light interception based on the point grid method (Wünsche et al. 1995). Percentage of shadow projected under the canopy on a grid of 19 to 35 frame of $1 \times$ $0.5 \mathrm{~m}$. Each frame was photographed and the percentage of shaded area was calculated over the total area using the IMAGE J 1.49v software (Rasband, National Institutes of Health, U.S.A.) (Zarate-Valdez et al. 2015). Values shown from S2 at harvest.

c The microsprinklers were $100 \mathrm{~cm}$ above the ground.

$\mathrm{d}$ The microsprinklers were $30 \mathrm{~cm}$ above the ground.

e Iprodione (Rovral 4Flow, Bayer; 2.5 liter ha ${ }^{-1}$ ) or fenhexamid (Teldor, Bayer; 1.2 liter ha ${ }^{-1}$ ) were applied at full bloom and 1 week before harvest in both growing seasons at rates recommended to control gray mold control. 
gently hand brushed to remove all senescent floral debris (necrotic petals, stamens, and styles). Fruit were then surface-disinfected as was described for floral parts, washed in sterile water for $1 \mathrm{~min}$, dried for $15 \mathrm{~min}$ in a laminar flow, and frozen for $24 \mathrm{~h}$ at $-20^{\circ} \mathrm{C}$ ( Holz et al. 2003; Sanzani et al. 2012). Subsequently, fruit were incubated in a moist chamber at $20^{\circ} \mathrm{C}$. Infection by $B$. cinerea was confirmed by noting the presence of soft decay with light brown pulp and the abundant gray aerial mycelia at the stem end. The kiwifruit infection was assessed after 6 days, and symptomatic fruit were retained for an additional 4 days, awaiting corroboration by sporulation. Pieces of tissues were immediately taken from under the receptacle from asymptomatic and symptomatic fruit, plated on APDA for 7 days at $20^{\circ} \mathrm{C}$ to determine the presence of $B$. cinerea. The development of symptoms of SER and the signs of $B$. cinerea in apparently healthy fruit after the freezing treatment were considered to be latent infections.

Incidence of stem end rot during storage. Stem end rot incidence in kiwifruit was evaluated after 100 days of storage at $0^{\circ} \mathrm{C}$ plus 2 days at $20^{\circ} \mathrm{C}$ from totals of 320 fruit per orchard. Fruit were hand brushed and their peduncles removed by hand, cured for $24 \mathrm{~h}$ at $20^{\circ} \mathrm{C}$, and packed in $10 \mathrm{~kg}$ capacity cardboard boxes with $60-\mu \mathrm{m}$-thick, lowdensity polyethylene modified atmosphere bags (MAP, Fresh-Fresh Kiwi, San Jorge Packaging, Santiago, Chile). The fruit were stored in an ethylene-free environment produced by passing the incoming air stream through a potassium permanganate (Bioconservacion, $\mathrm{BCN}$, Spain) ethylene scrubber. The ethylene concentration was monitored every 2 days, maintaining ethylene concentrations consistently at $<0.005 \mu \mathrm{l} \mathrm{liter}{ }^{-1}$ (Zoffoli et al. 2016). Stem end rot incidence was expressed as the percentage of diseased fruit.

Microclimate characterization. Considering that environmental conditions are relevant variables affecting pathogen infection; temperature, relative humidity, leaf wetness, and rainfall were monitored in each orchard using sensors located in horizontal position, $1.8 \mathrm{~m}$ above the ground and below the kiwifruit canopy. Temperature and relative humidity were recorded using a data logger (U12 Temp / RH / 2 External Channel Logger, HOBO Onset, Computer Corporation, MA, U.S.A.). Leaf wetness duration (WET) was recorded using a dielectric leaf wetness sensor (Echo Decagon Devices, WA, U.S.A.), and the time duration was expressed in hours. All devices recorded at 15-min intervals from $60 \mathrm{DAFB}$ in $\mathrm{S} 1$ and from full bloom to harvest in $\mathrm{S} 2$. Mean daily temperature $\left(\mathrm{Tm}, \pm 0.35^{\circ} \mathrm{C}\right)$ and mean relative humidity $(\mathrm{RH}, \pm 2.5 \%$ ) were calculated. Vapor pressure deficit ( $V p d, \mathrm{kPa}$ ) was calculated as (Kaye and Laby 1957):

$$
V p d=V p\left(1-\frac{\mathrm{RH}}{100}\right)
$$

Where water vapor pressure $(V p)$ was:

$$
V p=4.6698 e^{0.06241 \mathrm{Tm}}
$$

Growing degree days (GDD) were calculated from full bloom to harvest using Tm with a threshold value of $10^{\circ} \mathrm{C}$ (Salinger and Kenny
1995). Rainfall data (mm), Tm, and HR from full bloom to 60 DAFB in $\mathrm{S} 1$ were obtained from weather data recorded by meteorological stations located in each of the orchards.

Infection periods. The weather data collected were used to calculate the number of infection periods for $B$. cinerea that occurred within each 20-day period from full bloom. The infection periods were determined using the model proposed for $B$. cinerea infection on table grapes (Broome et al. 1995). One infection period was recorded if the temperature fluctuated between 14 and $25^{\circ} \mathrm{C}$ and if leaf wetness occurred continuously for $6 \mathrm{~h}$ or more. An infection period was not counted if, during such a period, the conditions favoring infection (described above) were interrupted continuously for $>4 \mathrm{~h}$.

Statistical analyses. The dynamic of ACC and colonization of sepals, receptacles, styles, and latent infection in fruit during the growing season (DAFB) were explained with best-fit models using $P \leq 0.05$.

Stem end rot differences between orchards were determined by ANOVA. Mean differences were separated using the Fisher least significant difference (LSD) test $(P \leq 0.05)$. Percentage values of SER were transformed to arcsine square root prior to analysis.

Pearson's correlation was used to determine associations between ACC, B. cinerea colonization in sepals, receptacles, styles, latent infection in fruit, and SER incidence with $(P \leq 0.05)$.

The relationship between the accumulated number of infectionrisk periods and SER at harvest was determined using the best statistical model.

The analyses were carried out using the statistical software SigmaPlot v 12.5 (Systat Software Inc., San Jose, CA, U.S.A.).

\section{Results}

B. cinerea identification. B. cinerea $(n=5)$ and B. prunorum $(n=5)$ were identified from isolates cultured in APDA obtained from airborne conidial capture plates, petals, sepals, receptacles, styles, and fruit. $B$. cinerea colonies were white to gray and cottony with abundant sporulation on erect and free conidiophores, branched at the top with ellipsoidal, ovoid to globose nonseptated and hyaline conidia of size $9.2 \pm 0.8 \times 7.1 \pm 0.9 \mu \mathrm{m}$. B. prunorum colonies were white, fluffy, and cottony with nil to low sporulation in erect conidiophores with ellipsoidal to ovoid conidia with a slightly protuberant hilum of size $11.8 \pm 1.6 \times 6.9 \pm 0.9 \mu \mathrm{m}$. The $B$. prunorum counts were combined with the $B$. cinerea ones because of the low colonization values obtained $(<3 \%)$. A BLASTn search analysis using the HSP60 fragment gene sequence of all isolates in the study corroborated the identity of between 99 and $100 \%$ of $B$. cinerea and B. prunorum.

Microclimate conditions. In both seasons, CV and SMV experienced a typical Mediterranean summer (Table 2). The GDD from full bloom to harvest varied from 1,324 to 1,379 GDD in S1 and from 1,189 to 1,373 GDD in S2. The average daily maximum temperature was recorded between December and February (60-100 DAFB) averaging $19.8 \pm 0.9^{\circ} \mathrm{C}$ in $\mathrm{S} 1$ and $20.1 \pm 1.3^{\circ} \mathrm{C}$ in $\mathrm{S} 2$.

\begin{tabular}{|c|c|c|c|c|c|c|c|c|c|c|}
\hline \multirow[b]{2}{*}{ Valley } & \multicolumn{2}{|c|}{ GDD $\left({ }^{\circ} \mathbf{C}\right)^{\mathbf{a}}$} & \multicolumn{2}{|c|}{$\operatorname{Tm}\left({ }^{\circ} \mathbf{C}\right)^{\mathbf{b}}$} & \multicolumn{2}{|c|}{ RH $(\%)^{\mathrm{c}}$} & \multicolumn{2}{|c|}{ Vpd $(\mathrm{kPa})^{\mathrm{d}}$} & \multicolumn{2}{|c|}{ WET $(h)^{\mathrm{e}}$} \\
\hline & S1 & S2 & S1 & S2 & S1 & S2 & S1 & S2 & S1 & S2 \\
\hline \multicolumn{11}{|c|}{ Cachapoal Valley (CV) } \\
\hline $\mathrm{O} 1$ & 1,324 & 1,373 & 18.2 & 18.3 & 74.7 & 75.3 & 3.9 & 3.7 & $1,130.9$ & 499.6 \\
\hline $\mathrm{O} 2$ & 1,354 & 1,189 & 18.3 & 18.7 & 71.1 & 73.4 & 4.5 & 4.0 & 680.8 & 1190.0 \\
\hline $\mathrm{O} 3$ & 1,379 & 1,360 & 18.2 & 18.9 & 71.6 & 70.4 & 4.4 & 4.6 & 784.6 & 177.7 \\
\hline Mean & 1,353 & 1,307 & 18.2 & 18.6 & 72.5 & 73.0 & 4.3 & 4.1 & 865.42 & 622.44 \\
\hline \multicolumn{11}{|c|}{ South of Maule Valley (SMV) } \\
\hline O4 & 1,359 & 1,373 & 17.7 & 20.1 & 73.6 & 67.0 & 3.9 & 5.4 & 790.5 & 245.8 \\
\hline O5 & 1,311 & 1,359 & 17.8 & 19.6 & 73.5 & 68.1 & 3.9 & 5.1 & 785.5 & 496.3 \\
\hline Mean & 1,335 & 1,366 & 17.7 & 19.8 & 73.6 & 67.6 & 3.9 & 5.2 & 788.0 & 371.1 \\
\hline
\end{tabular}

Table 2. The microclimate of 'Hayward' kiwifruit orchards in Cachapoal Valley and South of Maule Valley from full bloom to harvest in S1 (2016) and S2 (2017)

a Growing degree day accumulation base $10^{\circ} \mathrm{C}$ from full bloom to harvest.

$\mathrm{b}$ Mean daily temperature $(\mathrm{Tm})$.

${ }^{\mathrm{c}}$ Mean daily relative humidity $(\mathrm{RH})$.

${ }^{\mathrm{d}}$ Vapor pressure deficit (Vpd).

e Accumulated leaf wetness duration (WET) from full bloom to harvest. 
Rainfall was greater in $\mathrm{S} 1$ than in $\mathrm{S} 2$. The total accumulated rainfall in $\mathrm{S} 1$ recorded $125 \mathrm{~mm}$ in $\mathrm{CV}$ and $83 \mathrm{~mm}$ in SMV. In the last period before harvest, the rainfall recorded $104.7 \mathrm{~mm}$ in $\mathrm{CV}$ and $60.2 \mathrm{~mm}$ in SMV. In contrast, no important rainfall events occurred in CV $(2.9 \mathrm{~mm})$ or SMV (41.0 mm) during S2.

The average of accumulated WET duration in CV was $865 \mathrm{~h}$ (S1) and $662 \mathrm{~h}$ (S2), while the equivalent values for SMV were $788 \mathrm{~h}$ (S1) and $371 \mathrm{~h}$ (S2) (Table 2).

Airborne conidial concentration. The concentrations of airborne B. cinerea conidia averaged $674 \mathrm{CFU} \mathrm{m}^{-3}$ (from $60 \mathrm{DAFB}$ to harvest) in $\mathrm{S} 1$ and $177 \mathrm{CFU} \mathrm{m}{ }^{-3}$ (from 0 DAFB to harvest) in S2 (Fig. 1).

In S1, ACC temporal dynamics were similar between CV and SMV; these are both satisfactorily fitted by quadratic regressions $(P<0.001)$. The concentrations were always higher in CV than in $\mathrm{SMV}$; the averages were $685 \mathrm{CFU} \mathrm{m}^{-3}$ in $\mathrm{CV}$ and $288 \mathrm{CFU} \mathrm{m}^{-3}$ in SMV. The highest concentrations were obtained at the end of the season with maxima of $2,293 \mathrm{CFU} \mathrm{m}^{-3}$ in $\mathrm{CV}$ and $770 \mathrm{CFU}$ $\mathrm{m}^{-3}$ in SMV (Fig. 1A). In S2, mean ACC values were 3.8-fold lower than those in $\mathrm{S} 1$ and were similar between $\mathrm{CV}$ and SMV throughout the season. The highest values of ACC in S2 occurred on 80 DAFB in $\mathrm{CV}\left(352 \mathrm{CFU} \mathrm{m}^{-3}\right)$ and on $60 \mathrm{DAFB}$ in SMV $\left(379 \mathrm{CFU} \mathrm{m}^{-3}\right)$, while the lowest values were at harvest in $\mathrm{CV}\left(27 \mathrm{CFU} \mathrm{m}^{-3}\right)$ and at 120 DAFB in SMV (41 CFU m ${ }^{-3}$ ) (Fig. 1B).

$B$. cinerea in floral parts and latent infections in fruit. Floral parts. B. cinerea was consistently isolated from asymptomatic petals, sepals, receptacles, and styles (Fig. 2). The temporal dynamics differed significantly between seasons (S1 and S2) and locations (CV and SMV).

Across all floral parts, the levels of B. cinerea found in the CV orchards were similar or higher than those in the SMV orchards. This was true across both seasons. Levels were either constant or increased toward harvest in S1. However, no clear temporal pattern emerged during S2. In S1 and S2, respectively, the mean frequencies of isolation were: 15.1 and $21.4 \%$ in the sepals, 24.0 and $26.1 \%$ in the receptacles, and 14.8 and $6.4 \%$ in the styles. In S2, the average colonization of petals by $B$. cinerea was $70.9 \%$.

In $S 1$, the temporal dynamics of B. cinerea in sepals, receptacles, and styles were significantly explained by quadratic regressions, with the exception of the sepals in SMV, where little variation occurred with time. In the sepals, the frequency of isolation averaged $18.8 \%$ with a slight increase at harvest (Fig. 2C). In the receptacles, the frequency of $B$. cinerea averaged $25.6 \%$ in $\mathrm{CV}$ and $22.4 \%$ in SMV (Fig. 2E). The highest levels of B. cinerea in the styles was at harvest when the levels averaged $17.0 \%$ in CV and $13.2 \%$ in SMV (Fig. 2G).
In $\mathrm{S} 2$, the temporal dynamics of $B$. cinerea either decreased or was constant with time. The isolation frequency in the sepals decreased linearly from bloom $(45.9 \%)$ to harvest $(14.6 \%)$ in $\mathrm{CV}\left(\mathrm{R}^{2}=0.32\right.$, $P<0.001)$ (Fig. 2D). The isolation frequency through the season remained constant in SMV, averaging $12.7 \%$. In the receptacles, no significant relationship was found between $B$. cinerea isolation frequency and time in CV (Fig. 2F). Meanwhile, in SMV, the isolation frequency increased between 80 and 120 DAFB and then decreased to harvest. In the styles, the $B$. cinerea isolation frequency remained low and constant in both CV and SMV (Fig. 2H).

Incidence of latent infection in fruit. During S1, fruit with latent B. cinerea infections developed abundant aerial mycelia and light brown pulp in the stem end at each sampling day. The averages across sampling days were $49.8 \%$ in S1 and $2.7 \%$ in S2.

In general, similar latent infections occurred with time in CV in S1, values ranging from 40 to $60 \%$ until harvest. Meanwhile, in SMV, the latent infection rate decreased from $65 \%$ and to $40 \%$ (Fig. 3A). In S2, the latent infection rates were low $(<10 \%)$, remained constant with time, and were not significantly explained by a linear regression (Fig. 3B).

Stem end rot incidence in storage. Stem end rot developed in fruit stored at $0^{\circ} \mathrm{C}$ for 100 days with significantly different incidences between seasons and orchards. Mean incidence varied between seasons, being $31.5 \%$ in $\mathrm{S} 1$ and $6.6 \%$ in $\mathrm{S} 2(P<0.001)$. In $\mathrm{S} 1$, the SER incidence varied between a low of $1.9 \%$ in $\mathrm{O} 4$ and a high of $60.3 \%$ in $\mathrm{O} 3$. In $\mathrm{S} 2$, the mean incidence was 2.8 -fold lower than in S1 and did not differ significantly between orchards $(P=0.14)$ (Fig. 4).

Infection periods. Environmental conditions favoring B. cinerea infection were recorded from full bloom to harvest in $\mathrm{S} 1$. The number of infection periods ranged from a maximum of 18 in $\mathrm{O} 3$ to a minimum of 11 in O4, which were concentrated at 80 DAFB and at harvest (Fig. 5A). At least one period of infection occurred during each time interval except for from 0 to 40 DAFB in which none were recorded. The second season was drier and less conducive to infection. There were four infection periods in $\mathrm{O} 1, \mathrm{O} 4$, and $\mathrm{O} 5$ and none in $\mathrm{O} 2$ and $\mathrm{O} 3$ (Fig. 5B). A positive relationship between the cumulated number of infection periods from full bloom to harvest and SER in cold storage was observed $(\mathrm{r}=0.95)$. This relationship is best represented by the exponential model $\left(y=\exp (0.23 x), \mathrm{R}^{2}=0.90, P<\right.$ $0.001)$ where $x=$ the cumulative number of infection periods and $y=$ the incidence of SER (\%) (Fig. 6). To illustrate this positive relationship by two examples, when the number of infection periods exceeded 15, the percentage of infected fruit was approximately

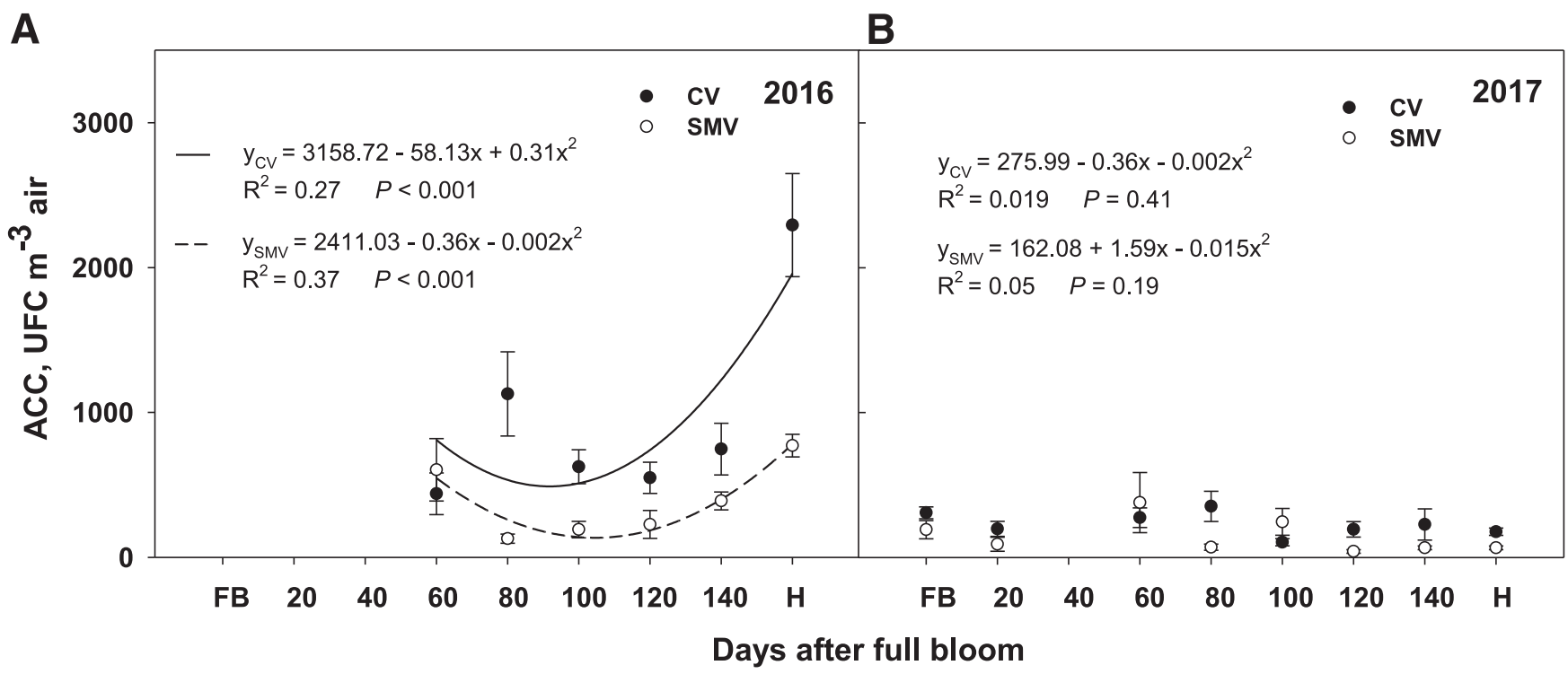

Fig. 1. Mean airborne conidial concentration (ACC) of Botrytis cinerea of five 'Hayward' kiwifruit orchards located in Cachapoal Valley (CV: Orchards 1,2, and 3) and South of Maule Valley (SMV: Orchards 4 and 5) from full bloom (FB) to harvest (H). A, Season 2016 (S1). B, Season 2017 (S2). Mean values were obtained from the average of 4 replicates of 3 measures each. Vertical bar $=$ standard error. Regressions were significant when $P \leq 0.05$. 
$30 \%$, while when there were 17 infection periods, the percentage of infected fruit exceeded $50 \%$.

Relationships between colonization in floral parts and latent infections in fruit with stem end rot incidence during storage. Pearson's coefficients (r) were used to describe the relationships between $B$. cinerea colonization in floral parts or as latent infections in fruits observed from full bloom or from 60 DAFB to harvest and the subsequent SER incidence during storage in both seasons. In S1, the relationships were positive and significant with the highest values between 140 DAFB and harvest (Fig. 7A). In S2, significant relationships were found between colonization and SER in the sepals $(r=$ $0.47)$ and the styles $(r=0.47)$ at full bloom and the styles at harvest $(\mathrm{r}=0.56)$ (Fig. 7B). To obtain a more robust result, given the two contrasting seasons, the S1 and S2 data were combined and used to determine the relationship between SER and the presence of $B$. cinerea in each tissue and at each sampling date. The significance

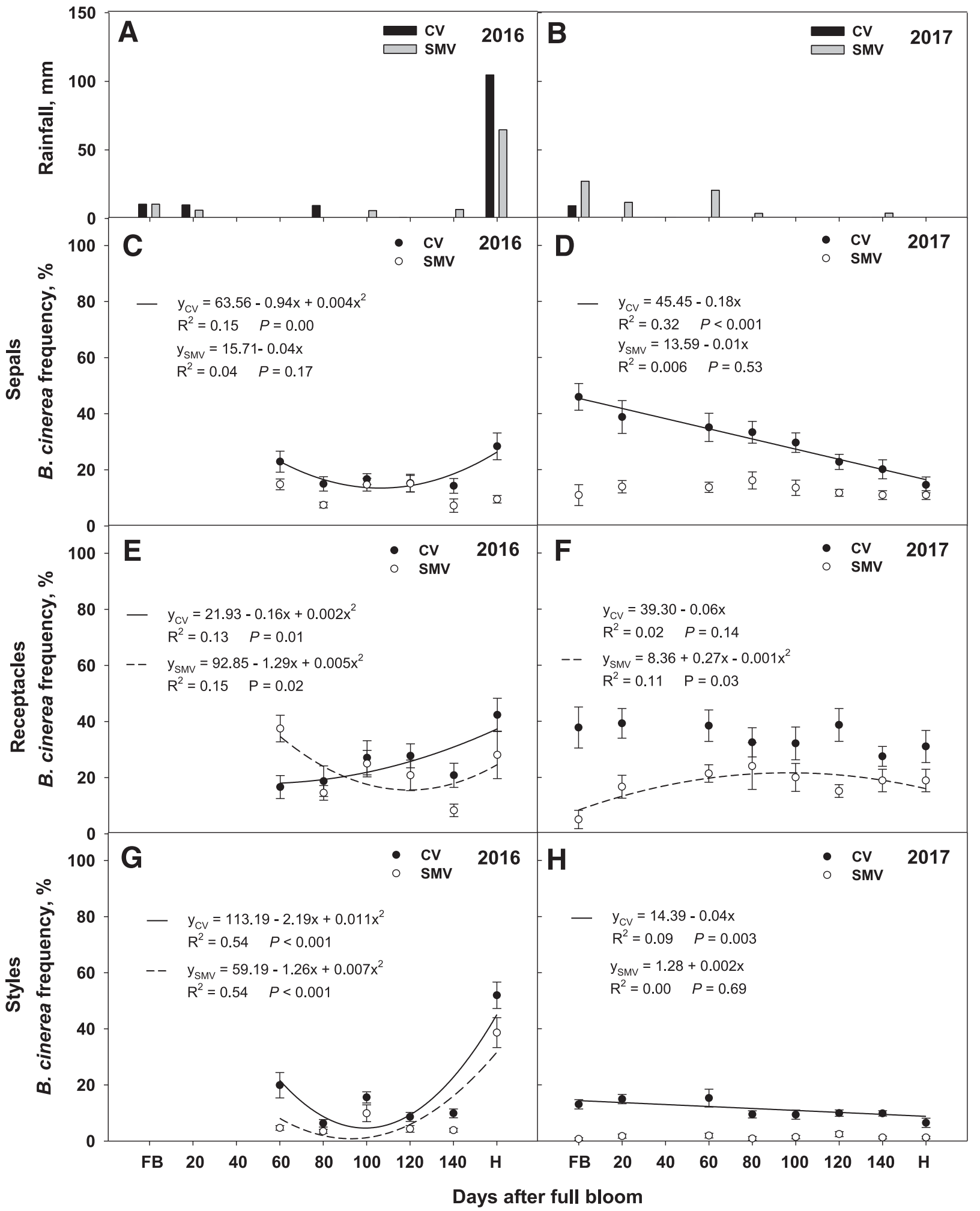

Fig. 2. Cumulated rainfall $(A, B)$ and temporal dynamic of Botrytis cinerea affecting sepals (C, D), receptacles (E, F), and styles (G, H) of 'Hayward' kiwifruit from full bloom ( $F B$ ) to harvest $(H)$ in five orchards located in Cachapoal Valley (CV) and South of Maule Valley (SMV) in 2016 season (A, C, E, G) and 2017 season (B, D, F, H). Vertical bar = standard error. Regressions were significant when $P \leq 0.05$. 
of Pearson's coefficients for all variables increased from full bloom to the end of the season, with the highest values at harvest (Fig. 7C). All variables at harvest were significantly related to the postharvest incidence of SER. The style colonization was positively and significantly related to SER from 120 DAFB until harvest $(r=0.75)$ (Fig. 7C). Receptacle colonization was significantly related to SER only at harvest, while sepal colonization was significantly related to SER only at full bloom (only measured in S2) and at harvest (both seasons). The most significant $(\mathrm{r}=0.8)$ and consistent relation was between latent $B$. cinerea infections of the fruit through the season and SER.

\section{Discussion}

The temporal dynamics of $B$. cinerea colonization associated with floral parts and fruit was studied during fruit development, in five
'Hayward' kiwifruit orchards in two regions and over two growing seasons $(2016,2017)$. Using this information, we were able to identify the best 'indicator' tissue, i.e., latent infections of fruit, to predict the later incidence of SER during cold storage. B. cinerea colonized all floral parts, and the key sources of inoculum associated with SER were the style from 120 DAFB until harvest, the receptacle at harvest, and the sepals at full bloom and harvest. Otherwise, environmental conditions affected the temporal dynamics, inoculum density of $B$. cinerea in the orchard, and the most important factors appear to be episodes of rainfall and surface wetness. Our study indicates that the presence of $B$. cinerea in all floral parts and latent infections of fruit were related with SER under wet season (S1). When data from wet (S1) and dry (S2) seasons were pulled and analyzed, incidence of latent infection was positively and significantly related to SER incidence from 60 DAFB to harvest.

A

B

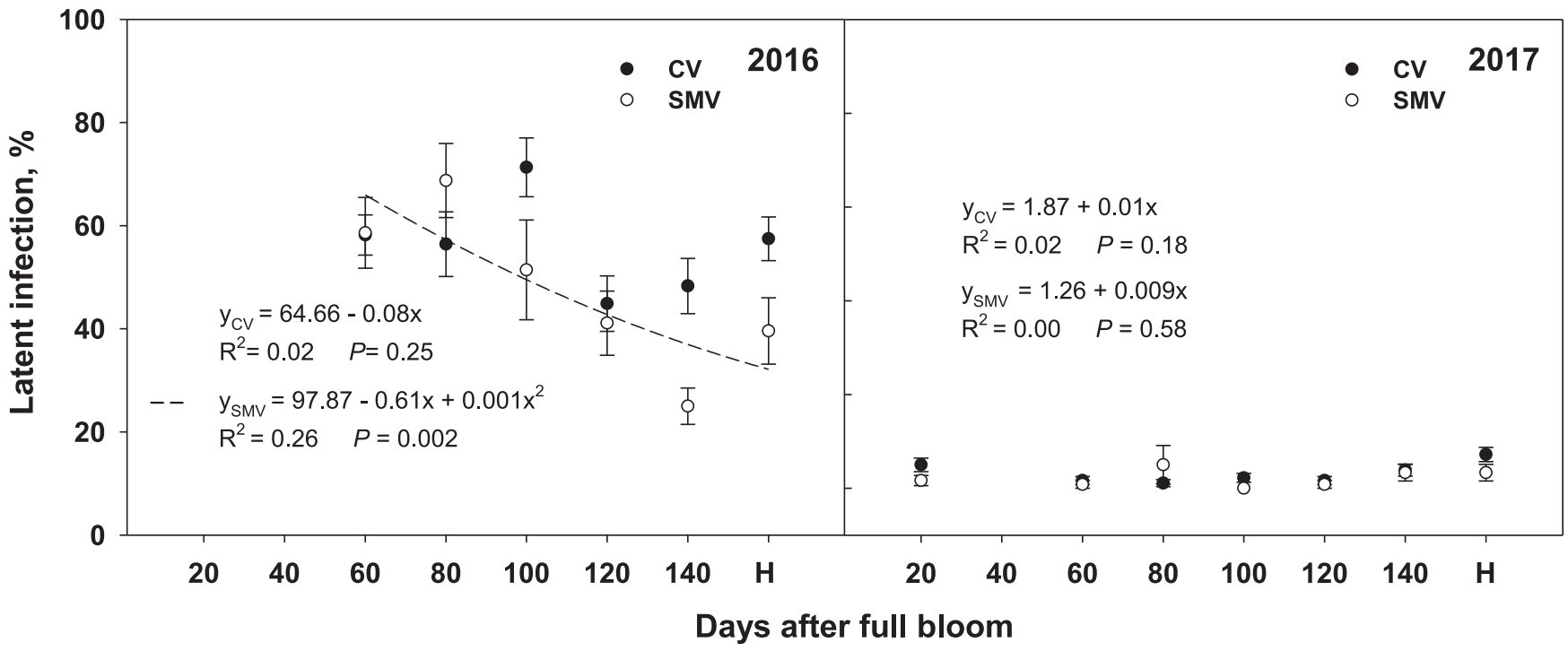

Fig. 3. Temporal dynamic of Botrytis cinerea latent infection in 'Hayward' kiwifruit from 20 DAFB to harvest $(\mathrm{H})$ of three orchards in Cachapoal Valley (CV) and two in South of Maule Valley (SMV). A, 2016 season. B, 2017 season. Latent infection was determined after $6-10$ days of incubation at $20^{\circ} \mathrm{C}$ in a wet chamber prior to overnight freezing incubation technique $(n=15,4$ replicates). Vertical bar $=$ standard error. Regressions were significant when $P \leq 0.05$.

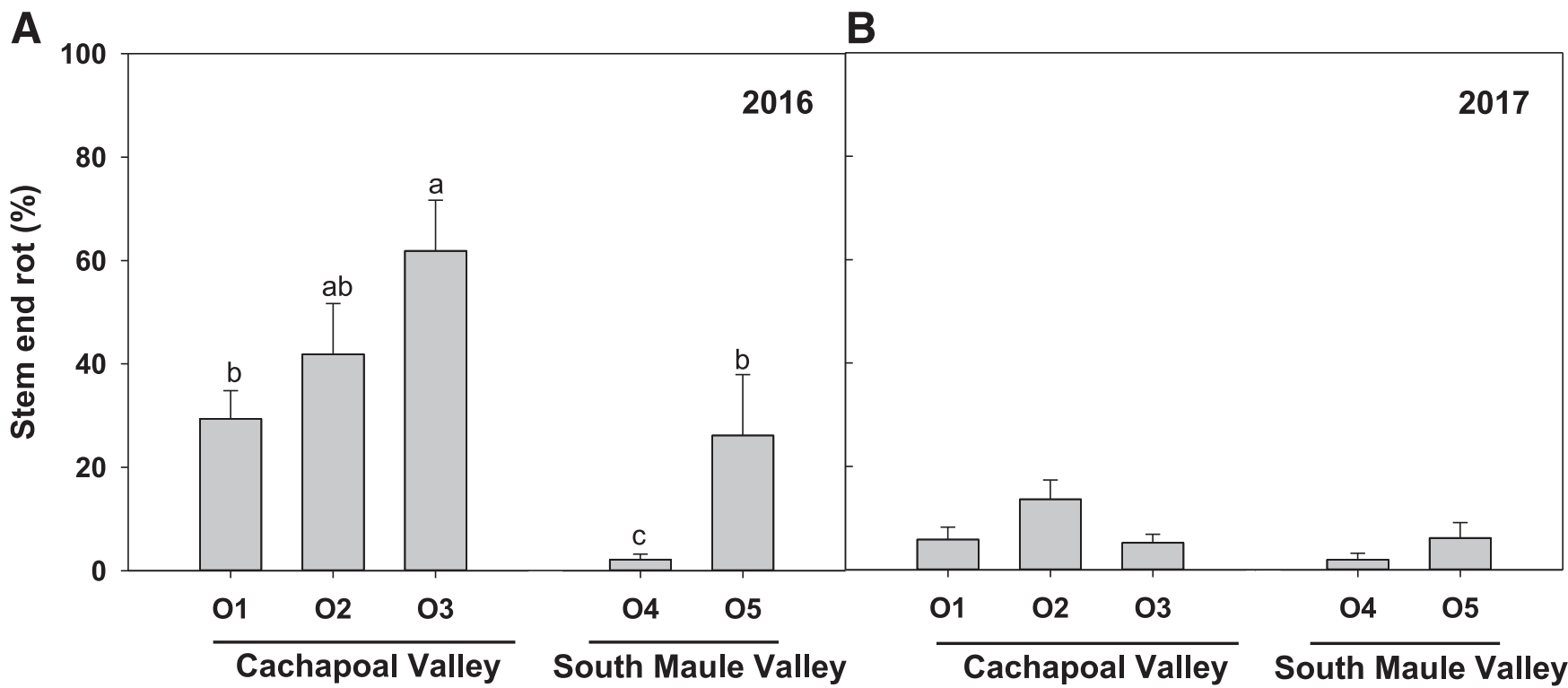

Fig. 4. Stem end rot incidence (\%) after 100 days at $0^{\circ} \mathrm{C}$ plus 2 days at $20^{\circ} \mathrm{C}$ in five 'Hayward' kiwifruit orchards located in Cachapoal Valley (Orchards 1,2 , and 3 ) and South of Maule Valley (Orchards 4 and 5). A, 2016 growing season. B, 2017 growing season. Vertical bars = the standard error of four replicates of 80 fruit each. Means followed by the same letter indicate significant differences according to Fisher LSD $(P \leq 0.05)$. 
Notwithstanding the application of a botryticide at full bloom in both seasons, the colonization of $B$. cinerea was demonstrated in all floral parts evaluated. This result indicates $B$. cinerea is a component of the mycoflora of flowers and fruit and that it is able to survive through the season within these inoculum sources. In this study, the temporal dynamics of $B$. cinerea in $\mathrm{S} 1$ was similar to the results obtained by Michailides and Morgan (1996) in California, with the highest values of Botrytis colonization at the end of the season. The high wetness duration due recurrent rainfall events along with warm temperature $\left(14^{\circ} \mathrm{C}\right.$ to $\left.25^{\circ} \mathrm{C}\right)$ before harvest would seem to explain, in this study, the high values of colonization at the end of S1. In grapes, Hill et al. (2019) showed that RH and surface wetness duration were key environmental determinants of Botrytis epidemics, and similar results were obtained in blueberry (Rivera et al. 2013).

Weather conditions and cultural practices (Snelgar et al. 1998) both influence fruit microclimate and so directly affect the colonization of B. cinerea (Elmer et al. 1997; English et al. 1989; Latorre et al. 2015; Valdés-Gómez et al. 2008). Favorable environmental conditions as temperatures between $15^{\circ} \mathrm{C}$ and $20^{\circ} \mathrm{C}$ along with relative humidity $>65.5 \%$ then lead to sporulation and, in the presence of free moisture, subsequent infection of the fruit (Ciliberti et al. 2016). English et al. (1989) determined that temperature, vapor pressure, wind speed, and leaf wetness under the canopy of grapevines are critical variables that affect Botrytis infection in grape. For example, in our study, Orchards 4 and 5 in SMV had more transparent canopy and reached the lowest cumulated infection periods at harvest and thus, lead the lowest colonization by $B$. cinerea in sepals and styles in both years and the lowest SER incidence in $S 1$, reaffirming the prime importance of environmental conditions to $B$. cinerea infection. Therefore, strategies with a holistic approach are suggested to reduce the infection during the season in kiwifruit orchards.

The analysis of leaf wetness duration in the CV and SMV orchards, integrated with $\mathrm{Tm}$ in an algorithm, allowed us to quantify conditions that favored B. cinerea infection in both $\mathrm{S} 1$ and $\mathrm{S} 2$.

Models using microclimatic factors to predict Botrytis infections in a range of hosts have been developed both under controlled conditions

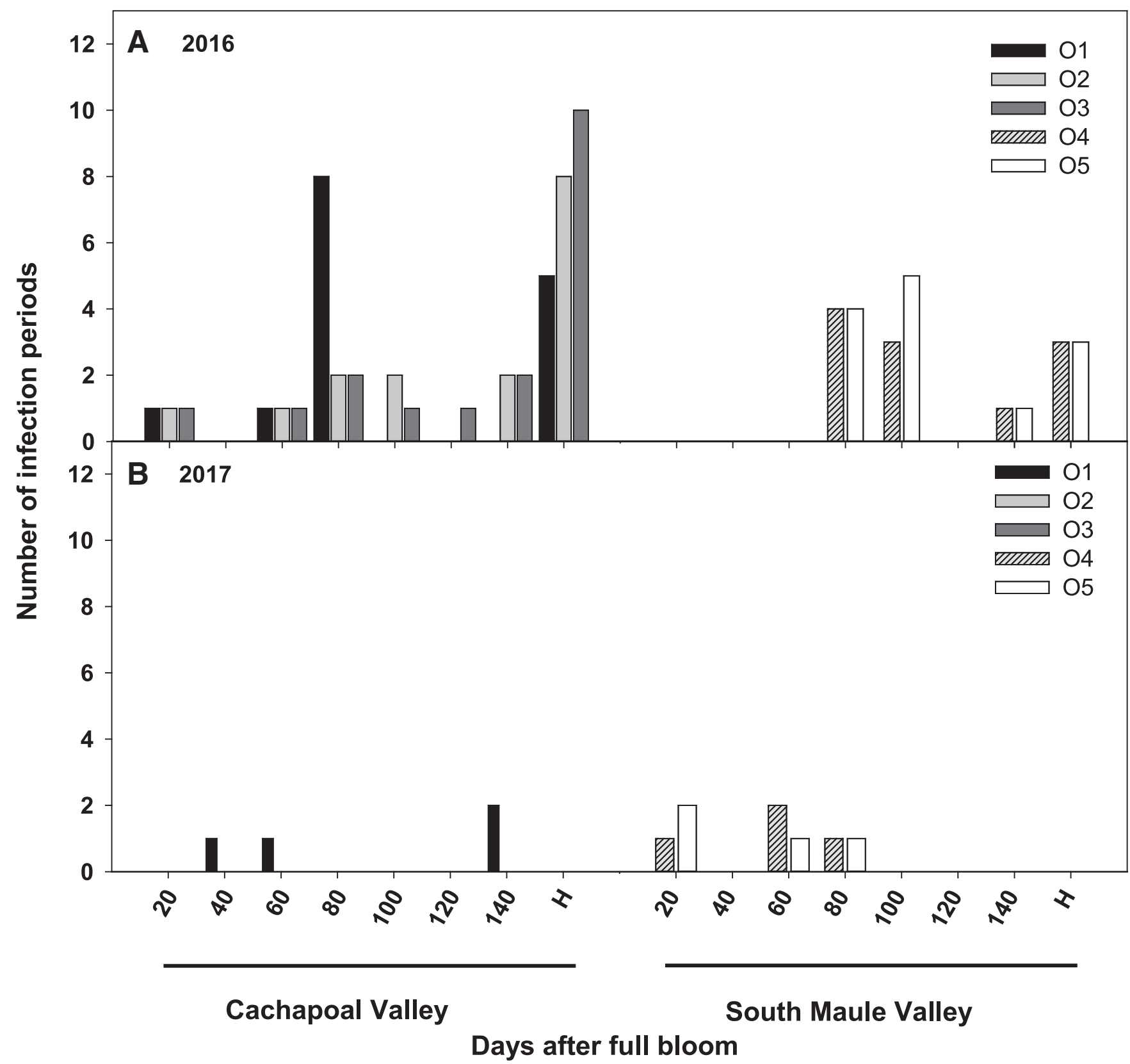

Fig. 5. Infection periods counted between full bloom to harvest in five orchards located in Cachapoal Valley (Orchards 1, 2, and 3) and South of Maule Valley (Orchards 4 and 5). A, 2016 season (S1). B, 2017 season (S2). One infection period was estimated if $14^{\circ} \mathrm{C}<\mathrm{T}<25^{\circ} \mathrm{C}, \mathrm{RH}>90 \%$ or leaf wetness for at least $6 \mathrm{~h}$ (Broome et al. 1995). T: mean temperature; $\mathrm{RH}$ : relative humidity. 
(Broome et al. 1995; Bulger et al. 1987) and under field conditions (Calvo-Garrido et al. 2014; Carisse et al. 2017). Similar to Rivera et al. (2013) with blueberries, we found an exponential model best explained the relation between the number of infection periods $\left(14^{\circ} \mathrm{C}\right.$ $<\mathrm{T}<25^{\circ} \mathrm{C},>90 \% \mathrm{RH}$ along with at least $6 \mathrm{~h}$ of wetness duration) and the incidence of postharvest decay. Our results show that with zero infection periods in $\mathrm{S} 2$, a few infected kiwifruits were nevertheless found during storage. This suggests environmental factors other than the ones we considered could be involved (Blanco et al. 2006; English et al. 1989). The inclusion of ACC has been found to improve models based on microclimatic factors that predict Botrytis-caused diseases (Blanco et al.2006; Carisse et al. 2017; Xu et al. 2000). Also, Carisse and McNealis (2018) reported a significant correlation between ACC and losses produced by Botrytis fruit rot in strawberry. In our results, the ACC differed between seasons, with higher mean values in $\mathrm{S} 1$ and lower ones in S2, which also fits with the levels of infection in the two seasons. The ACC changes daily depending on host tissue (Ciliberti et al. 2016; Jaspers et al. 2016) and environmental conditions favorable to sporulation and conidial release (Blanco et al. 2006; Sosa-Alvarez et al. 1995).

After ONFIT, previously asymptomatic kiwifruit developed abundant aerial mycelia and light brown pulp in the stem end, demonstrating that $B$. cinerea infections occur during fruit development. These latent infections were shown to be strongly associated with the development of SER during storage $(\mathrm{r}=0.8)$. Overall, the incidence of latent infections was high in S1 $(49.8 \%)$ and low in S2 $(2.7 \%)$. These data demonstrate that $B$. cinerea infections occur during fruit development. Latent infections of fruit by Botrytis spp. have been described in grapes (Holz et al. 2003; Sanzani et al. 2012), with full bloom being one of the periods when infection is most likely to occur (Keller et al. 2003; Nair et al. 1995). The results suggest that fruit susceptibility to $B$. cinerea was high before 60 DAFB, which agrees with the results of Riquelme et al. (2017), who reported that kiwifruit at 20 DAFB was susceptible to controlled inoculation of Botrytis spp. They also claim that immature fruit are more susceptible to Botrytis infection than mature ones, a result also observed by Wurms et al. (1998). However, this result does not clarify the relationship of the infection in flowering and the early stages of fruit with the appearance of SER during storage as has been explained in some other fruit species, such as table grapes at flowering (Keller et al. 2003; Nair and Allen 1993).

Since the need to predict SER is important, so that control measures can be implemented under high risk, correlation analysis using different tissues has been proposed. Among these, the percentage of

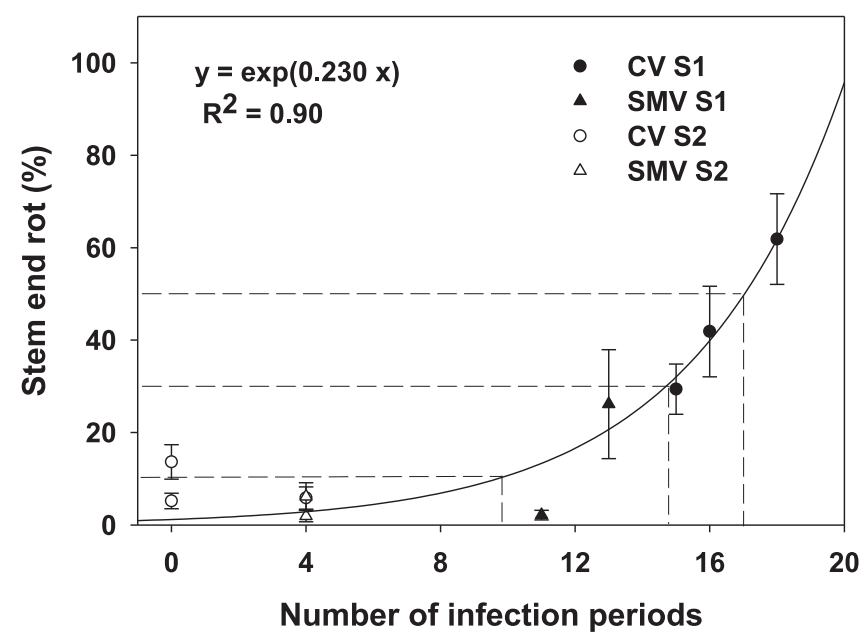

Fig. 6. Exponential relationship between the cumulated number of infection periods based on the algorithm of Botrytis cinerea model (Broome et al. 1995) from full bloom until harvest and stem end rot incidence after 100 days at $0^{\circ} \mathrm{C}$ plus 2 days at $20^{\circ} \mathrm{C}$. Stem end rot incidence was estimated from five kiwifruit orchards in 4 replicates of 80 fruit each season. Mean values from 2016 season (S1) in Cachapoal Valley (CV, solid circle) and South of Maule Valley (SMV, solid triangle) and from 2017 season (S2) in Cachapoal Valley (CV, open circle) and South of Maule Valley (SMV, open triangle) are shown. Vertical bars $=$ standard error. floral parts colonized by B. cinerea (Elmer et al. 1997; Michailides and Morgan 1996) and the inoculum density in leaf tissues (Manning et al. 2010) have proved good SER predictors in kiwifruit. Michailides et al. (2010) described latent infections in fruit as useful 'indicators' of a number of factors that might affect disease development in the orchard. These will include environmental conditions (Mari et al. 2003; Michailides and Morgan 1996) as well as cultural practices.

According to the relationship between the floral parts analyzed and SER incidence, style colonization showed the most positive and significant correlations with SER during the whole of S1, and also at full bloom and at harvest in S2. Nevertheless, this does not necessarily mean that style colonization is the most important inoculum source causing SER. On the contrary, the styles were less frequently colonized compared with the sepals and receptacles. This finding is supported by the previous work which indicates stylar rot in kiwifruit is unusual (Bisiach et al. 1984) and is not associated with postharvest

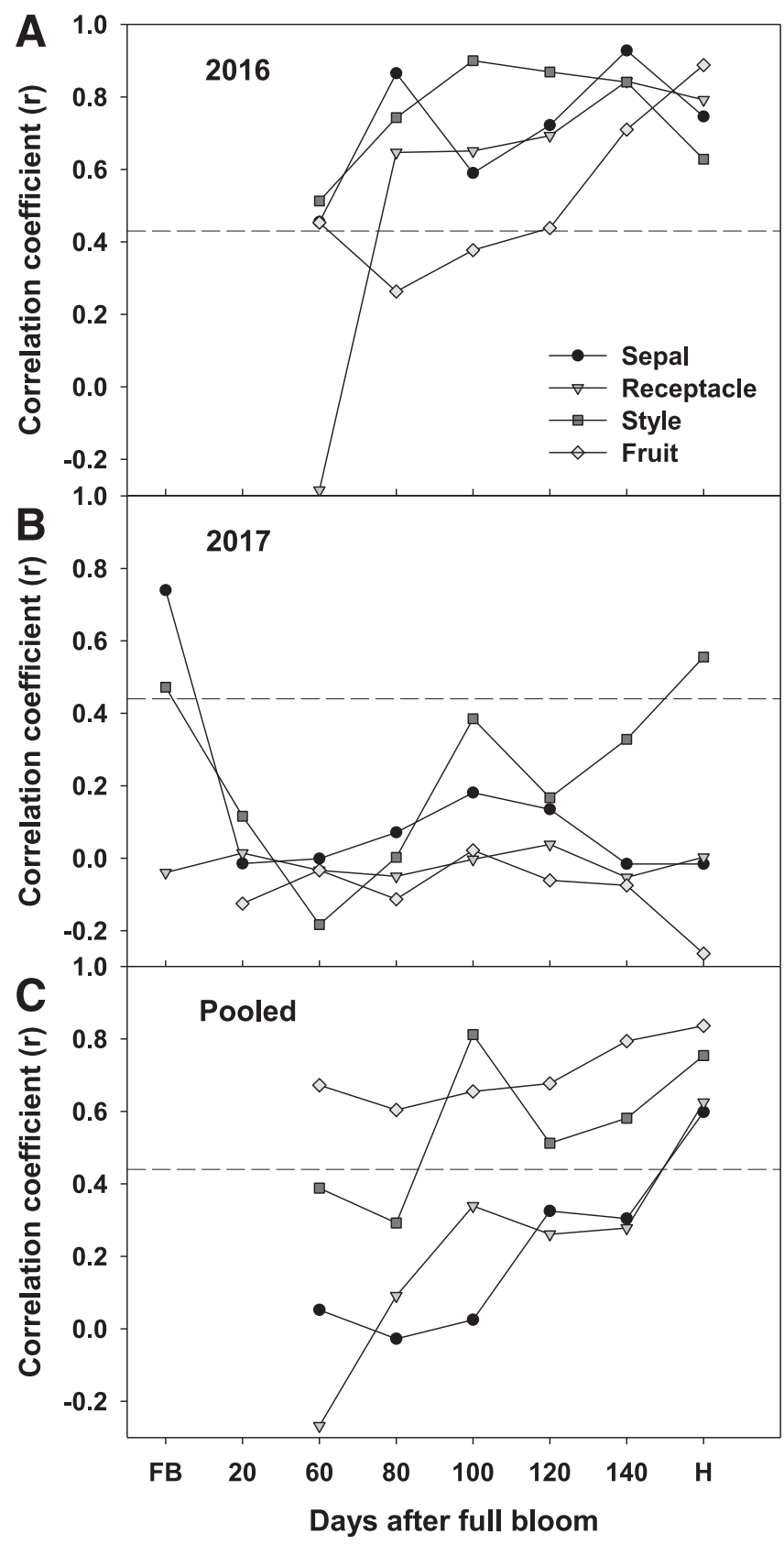

Fig. 7. Pearson's coefficients obtained from the correlations between postharvest stem end rot incidence and the presence of Botrytis cinerea in sepals, styles, receptacles, and latent infection in fruit, from full bloom (FB) to harvest (H). A, Season 2016 (S1). B, Season 2017 (S2). C, Pearson's coefficients were calculated using data from S1 and S2 at each sampling day. Values above dashed line indicate significant correlations $(P \leq 0.05)$. 
SER (Fermaud and Gaunt 1995). Therefore, these results reaffirm that colonization of floral parts may more closely reflect the environmental conditions of the season (Michailides et al. 2010).

It is important to realize that a kiwifruit is the result of the pollination of numerous styles (about 35 ) and reflects the fecundity of perhaps 1,000 ovules. Lastly, it is worth noting that petals fall just a few days after flowering, whereas the sepals and styles are retained by the fruit through to harvest, offering a substrate for $B$. cinerea throughout this roughly 5-month period from bloom to harvest. Hence these sources, rather than the very temporary petals, are more likely to infect the fruit. Symptoms of Botrytis infection during storage appear at the stem end, suggesting that it is the sepal and receptacle tissues that are in contact with the fruit. Of course, due to variable environmental conditions and the fruit's own disease defense mechanisms, not all these infected tissues will result in SER (Sharrock and Hallett 1992). Sepals and receptacle were significantly correlated with SER in this study during S1, similar to the results of a California study (Michailides and Morgan 1996). Also, SER infections rarely occur in some Chinese Actinidia cultivars (yellow-fleshed) such as 'Hort16A' or 'Jintao' where sepals hardly remain on the fruit (Manning et al. 2003).

In Chile, recording incidence of latent infections in kiwifruit can be indicative of years in which high incidence of SER (S1) will occur, or of low ones (S2). This advance warning of likely high or low SER is at least 2 months after full bloom and some 3 months before harvest. This is similar to the timing of analysis of methods recommended using level of colonization of $B$. cinerea in sepals and receptacles as predictors of SER (Michailides and Morgan 1996). Nevertheless, it is likely that not all infections on floral parts will result in latent infections of the fruit and then in a subsequent rot (Sanzani et al. 2012). In addition, the presence of latent infection by $B$. cinerea in grape berries using a quantitative real-time PCR (qPCR) detection method was demonstrated and with an efficiency higher than obtained from freezing technique (Sanzani et al. 2012) even at low inoculum pressure. However, values obtained from qPCR technique were highly correlated with freezing technique (Sanzani et al. 2012), indicating that both methods were similarly reliable. However, qPCR is an expensive method which requires skilled expertise, with specific facilities to be applied.

In summary, $B$. cinerea colonization of the floral parts remaining on the fruit was present during the whole season and was able to harbor latent infections in fruit early in the season. Microclimatic conditions played a significant role in the SER epidemiology, affecting the temporal dynamics of colonization and inoculum density by $B$. cinerea and determined the occurrence of a conducive season to infection or an unfavorable season as S1 instead of S2. Furthermore, latent infections detected by ONFIT from 60 DAFB in kiwifruit might be a valuable, practical, and straightforward tool for the early and accurate prediction of postharvest SER, and might be useful to producers for identifying plots or orchards with a potential high SER incidence, allowing timely application of control management and proper decisions about storage duration or proximity of destination markets. Nevertheless, we suggest further evaluation of this method be undertaken using fruit from multiple orchards, to more precisely determine the critical values needed to estimate the risk of significant losses due to SER during subsequent storage.

\section{Acknowledgments}

The authors are grateful to Jessica Rodriguez and Álvaro Cuevas for their advice and suggestions, and Berta Puebla and Álvaro Jara for their dedication and technical help during this project. The authors also thank San Francisco Lo Garcés export for allowing us to use their associated orchards.

\section{Literature Cited}

Adaskaveg, J., Förster, H., and Thompson, D. 2000. Identification and etiology of visible quiescent infections of Monilinia fructicola and Botrytis cinerea in sweet cherry fruit. Plant Dis. 84:328-333.

Beever, D., McGrath, H., Clarke, D., and Todd, M. 1984. Field application and residues of fungicide for the control of Botrytis storage rot of kiwifruit. N.Z. J. Exp. Agric. 12:339-346.

Biggs, A. 1995. Detection of latent infections in apple fruit with paraquat. Plant Dis. 79:1062-1067.
Bisiach, M., Minervini, G., and Vercesi, A. 1984. Biological and epidemiological aspects of the kiwifruit (Actinidia chinensis Planchon) rot caused by Botrytis cinerea Pers. Riv. Patol. Vegetale, S.IV, 20:38-55.

Blanco, C., De Los Santos, B., and Romero, F. 2006. Relationship between concentrations of Botrytis cinerea conidia in air, environmental conditions, and the incidence of grey mould in strawberry flowers and fruits. Eur. J. Plant Pathol. 114:415-425.

Broome, J., English, J., Marois, J., Latorre, B., and Aviles, J. 1995. Development of an infection model for Botrytis bunch rot of grapes based on wetness duration and temperature. Phytopathology 85:97-102.

Bulger, M., Ellis, M., and Madden, L. 1987. Influence of temperature and wetness duration on infection of strawberry flowers by Botrytis cinerea and disease incidence of fruit originating from infected flowers. Phytopathology 77: $1225-1230$

Calvo-Garrido, C., Usall, J., Viñas, I., Elmer, P., Cases, E., and Teixido, N. 2014 Potential secondary inoculum sources of Botrytis cinerea and their influence on bunch rot development in dry Mediterranean climate vineyards. Pest Manag. Sci. 70:922-930

Carisse, O., and McNealis, V. 2018. Identification of weather conditions associated with the occurrence, severity, and incidence of black seed disease of strawberry caused by Mycosphaerella fragariae. Phytopathology 108:83-93.

Carisse, O., McNealis, V., and Kriss, A. 2017. Association between weather variables, airborne inoculum concentration, and raspberry fruit rot caused by Botrytis cinerea. Phytopathology 44:1-48.

Ciliberti, N., Fermaud, M., Roudet, J., Languasco, L., and Rossi, V. 2016. Environmental effects on the production of Botrytis cinerea conidia on different media, grape bunch trash, and mature berries. Aust. J. Grape Wine Res. 22:262-270.

Elad, Y., and Evensen, K. 1995. Physiological aspects of resistance to Botrytis cinerea. Phytopathology 85:637-643.

Elfar, K., Riquelme, D., Zoffoli, J., and Latorre, B. 2017. First report of Botrytis prunorum causing fruit rot on kiwifruit in Chile. Plant Dis. 101:388.

Elmer, P., and Michailides, T. 2007. Epidemiology of Botrytis cinerea in orchards and vine crops. Pages 243-272 in: Botrytis: Biology, Pathology and Control Kluwer Academic Publishers, Dordrecht, The Netherlands.

Elmer, P. A. G., Whelan, H. G., Boyd-Wilson, K. S. H., and Pyke, N. B. 1997 Relationship between Botrytis cinerea inoculum in kiwifruit vines, contamination of the fruit surface at harvest and stem end rot in cool storage. Acta Hortic. 444:713-718.

Emery, K., Michailides, T., and Scherm, H. 2000. Incidence of latent infection of immature peach fruit by Monilinia fructicola and relationship to brown rot in Georgia. Plant Dis. 84:853-857.

English, J., Thomas, C., Marois, J., and Gubler, W. 1989. Microclimates of grapevine canopies associated with leaf removal and control of Botrytis bunch rot. Phytopathology 79:395-401.

Farías, E. 2009. Expresión de los manejos de huerto en la calidad de los kiwis en postcosecha. Rev. Fructicola 2:40-43.

Fermaud, M., and Gaunt, R. 1995. Thrips obscuratus as a potential vector of Botrytis cinerea in kiwifruit. Mycol. Res. 99:267-273.

Fernández Rodríguez, S., Tormo, R., Silva, I., and Gonzalo, Á. 2011. Two sampling methods for the petri dish detection of airborne fungi. Grana 50: 202-207.

Ferrada, E., Latorre, B., Zoffoli, J., and Castillo, A. 2016. Identification and characterization of Botrytis Blossom Blight of Japanese Plums caused by Botrytis cinerea and B. prunorum sp. nov. in Chile. Phytopathology 106 : 155-165.

Fourie, P., Holz, G., and Calitz, F. 2002. Occurrence of Botrytis cinerea and Monilinia laxa on nectarine and plum in Western Cape orchards, South Africa. Australas. Plant Pathol. 31:197-204.

Giraud, T., Fortini, D., Levis, C., Lamarque, C., Leroux, P., Lobuglio, K., and Brygoo, Y. 1999. Two sibling species of the Botrytis cinerea complex, transposa and vacuma, are found in sympatry on numerous host plants. Phytopathology 89:967-973.

Hill, G., Beresford, R., and Evans, K. 2019. Automated analysis of aggregated datasets to identify climatic predictors of Botrytis Bunch Rot in wine grapes. Phytopathology 109:84-95

Holz, G., Gütschow, M., Coertze, S., and Calitz, F. 2003. Occurrence of Botrytis cinerea and subsequent disease expression at different positions on leaves and bunches of grape. Plant Dis. 87:351-358.

Jarvis, W. 1994. Latent infections in the pre- and postharvest environment. HortScience 29:749-751.

Jaspers, M., Seyb, A., Trought, M., and Balasubramaniam, R. 2016. Necrotic grapevine material from the current season is a source of Botrytis cinerea inoculum. Eur. J. Plant Pathol. 144:811-820.

Kaye, G., and Laby, T. 1957. Tables of Physical and Chemical Constants and Some Mathematical Functions, 11th Ed. Longmans, Green and Co., London.

Keller, M., Viret, O., and Cole, F. 2003. Botrytis cinerea infection in grape flowers: Defense reaction, latency, and disease expression. Phytopathology 93:316-322.

Lallu, N., and Burdon, J. 2007. Experiences with recent postharvest technologies in kiwifruit. Acta Hortic. 733-741.

Latorre, B., Elfar, K., and Ferrada, E. 2015. Gray mold caused by Botrytis cinerea limits grape production in Chile. Cienc. Investig. Agrar. 42:305-330. 
Latorre, B., and Pak, H. 2003. Diseases of kiwifruit. Pages 291-306 in: Diseases of Tropical Fruit Crops, 1st Ed. R. Ploetz, ed. CABI Publishing, Oxon, UK.

Luo, Y., Ma, Z., and Michailides, T. J. 2001. Analysis of factors affecting latent infection and sporulation of Monilinia fructicola on prune fruit. Plant Dis. 85:999-1003.

Luo, Y., and Michailides, T. J. 2001. Factors affecting latent infection of prune fruit by Monilinia fructicola. Phytopathology 91:864-872.

Manning, M., Meier, X., Olsen, T., and Johnston, P. 2003. Fungi associated with fruit rots of Actinidia chinensis 'Hort 16A' in New Zealand. N.Z. J. Crop Hortic. Sci. 31:315-324

Manning, M., Pak, H., and Beresford, R. 2010. Non-fungicidal control of Botrytis storage rot in New Zealand kiwifruit though pre- and postharvest crop management. Pages 183-196 in: Postharvest Pathology: Plant Pathology in the 21st Century, Vol. 2. Springer Science+Business Media B. V., New York.

Mari, M., Casalini, L., Baraldi, E., Bertolini, P., and Pratella, G. 2003. Susceptibility of apricot and peach fruit to Monilinia laxa during phenological stages. Postharv. Biol. Technol. 30:105-109.

Martinez, F., Dubos, B., and Fermaud, M. 2005. The role of saprotrophy and virulence in the population dynamics of Botrytis cinerea in vineyards. Phytopathology 95:692-700.

Michailides, T., and Elmer, P. 2000. Botrytis gray mold of kiwifruit caused by Botrytis cinerea in the United States and New Zealand. Plant Dis. 84:208-223.

Michailides, T., and Morgan, D. 1996. Using incidence of Botrytis cinerea in kiwifruit sepals and receptacles to predict gray mold decay in storage. Plant Dis. 80:248-254.

Michailides, T., Morgan, D., and Luo, Y. 2010. Epidemiological assessment and postharvest disease incidence. Pages 69-88 in: Postharvest Pathology: Plant Pathology in the 21st Century, Vol. 2. Springer Science+Business Media B. V., New York.

Mirzaei, S., Goltapeh, E., Shams-Bakhsh, M., and Safaie, N. 2008. Identification of Botrytis spp. on plants grown in Iran. J. Phytopathol. 156:21-28.

Mundy, D., Agnew, R., and Wood, P. 2012. Grape tendrils as an inoculum source of Botrytis cinerea in vineyards - A review. N.Z. Plant Prot. 65:218-227.

Nair, N., and Allen, R. 1993. Infection of grape flowers and berries by Botrytis cinerea as a function of time and temperature. Mycol. Res. 97:1012-1014.

Nair, N., Guilbaud-Oultorfi, S., Barchia, I., and Emmett, R. 1995. Significance of carry over inoculum, flower infection and latency on the incidence of Botrytis cinerea in berries of grapevines at harvest in New South Wales. Aust. J. Exp. Agric. 35:1177-1180.

Northover, J., and Cerauskas, R. 1994. Detection and significance of symptomless latent infections of Monilinia fructicola in plums. Can. J. Plant Pathol. 16:30-36.

Park, Y., Im, M., and Gorinstein, S. 2015. Shelf life extension and antioxidant activity of 'Hayward' kiwifruit as a result of prestorage conditioning and 1methylcyclopropene treatment. J. Food Sci. Technol. 52:2711-2720.

Pei, Y., Tao, Q., Zheng, X., Li, Y., Sun, X., Li, Z., Qi, X., Xu, J., Zhang, M., Chen, H., Chang, X., Tang, H., Sui, L., and Gong, G. 2019. Phenotypic and genetic characterization of Botrytis cinerea population from kiwifruit in Sichuan Province, China. Plant Dis. 103:748-758.

Pennycook, S. 1985. Fungal fruit rots of Actinidia deliciosa (kiwifruit). N.Z. J. Exp. Agric. 13:289-299.

Pennycook, S., and Manning, M. 1992. Picking wound curing to reduce Botrytis storage rot of kiwifruit. N.Z. J. Crop Hortic. Sci. 20:357-360.
Poole, P., and McLeod, L. C. 1994. Development of resistance to picking wound entry Botrytis cinerea storage rots in kiwifruit. N.Z. J. Crop Hortic. Sci. 22: 387-392.

Prusky, D., Alkan, N., Mengiste, T., and Fluhr, R. 2013. Quiescent and necrotrophic lifestyle choice during postharvest disease development. Annu. Rev. Phytopathol. 51:155-176.

Prusky, D., Fuchs, Y., and Zauberman, G. 1981. A method for pre-harvest assessment of latent infections in fruits. Ann. Appl. Biol. 98:79-85.

Riquelme, D., Valdés-Gómez, H., and Zoffoli, J. P. 2017. Kiwifruit susceptibility to Botrytis cinerea and Botrytis prunorum during fruit development in Chile. (Abstr.) Phytopathology 107:S5.75.

Rivera, S., Zoffoli, J., and Latorre, B. 2013. Infection risk and critical period for the postharvest control of gray mold (Botrytis cinerea) on blueberry in Chile. Plan Dis. 97:1069-1074.

Salinger, M., and Kenny, G. 1995. Climate and kiwifruit cv. 'Hayward' 2. Regions in New Zealand suited for production. N.Z. J. Crop Hortic. Sci. 23:173-184.

Sanzani, S., Schena, L., De Cicco, V., and Ippolito, A. 2012. Early detection of Botrytis cinerea latent infections as a tool to improve postharvest quality of table grapes. Postharv. Biol. Technol. 68:64-71.

Sarricolea, P., Herrera-Ossandon, M., and Meseguer-Ruiz, Ó. 2017. Climatic regionalisation of continental Chile. J. Maps 13:66-73.

Sharrock, K., and Hallett, I. C. 1992. Physiology of Botrytis infection in kiwifruit. Acta Hortic. 551-558.

Snelgar, W., Hopkirk, G., Seelye, R., Martin, P., and Manson, P. 1998 Relationship between canopy density and fruit quality of kiwifruit. N.Z. J. Crop Hortic. Sci. 26:223-232.

Sosa-Alvarez, M., Madden, L., and Ellis, M. 1995. Effects of temperature and wetness duration on sporulation of Botrytis cinerea on strawberry leaf residues. Plant Dis. 79:609-615.

Valdés-Gómez, H., Fermaud, M., Roudet, J., Calonnec, A., and Gary, C. 2008 Grey mould incidence is reduced on grapevines with lower vegetative and reproductive growth. Crop Prot. 27:1174-1186.

Verhoeff, K. 1974. Latent infections by fungi. Annu. Rev. Phytopathol. 12:99-110.

Wünsche, J., Lakso, A., and Robinson, T. 1995. Comparison of four methods for estimating total light interception by apple trees of varying forms. HortScience 30:272-276.

Wurms, K., Long, P., and Ganesh, S. 1998. Influence of host and pathogen factors on disease incidence resulting from artificial inoculation of kiwifruit by Botrytis cinerea. N.Z. J. Crop Hortic. Sci. 26:215-222.

Wurms, K., Sharrock, K., Long, P., Greenwood, D., and Ganesh, S. 1997. Responses of chitinases in kiwifruit to curing and to long-term storage. N.Z. J. Crop Hortic. Sci. 25:213-220.

Xu, X., Harris, D., and Berrie, A. 2000. Modeling infection of strawberry flowers by Botrytis cinerea using field data. Phytopathology 90:1367-1374.

Zarate-Valdez, J., Metcalf, S., Stewart, W., Ustin, S., and Lampinen, B. 2015. Estimating light interception in tree crops with digital images of canopy shadow. Precis. Agric. 16:425-440.

Zoffoli, J., Flores, K., and D'Hainaut, D. 2016. Effect of ethylene on ripening of kiwifruit stored under controlled or modified atmosphere packaging and treated with 1-methylcyclopropene. J. Berry Res. 6:381-393. 